\title{
An unusual form of transcriptional silencing in yeast ribosomal DNA
}

\author{
Jeffrey S. Smith and Jef D. Boeke ${ }^{1}$ \\ Department of Molecular Biology and Genetics, Johns Hopkins University School of Medicine, \\ Baltimore, Maryland 21205 USA
}

\begin{abstract}
Generalized transcriptional repression of large chromosomal regions in Saccharomyces cerevisiae occurs at the silent mating loci and at telomeres and is mediated by the silent information regulator (SIR) genes. We have identified a novel form of transcriptional silencing in S. cerevisiae in the ribosomal DNA (rDNA) tandem array. Ty1 retrotransposons marked with a weakened URA3 gene (Ty1-mURA3) efficiently integrated into rDNA. The mURA3 marker in rDNA was transcriptionally silenced in a SIR2-dependent manner. MET15 and LEU2 were also partially silenced, indicating that rDNA silencing may be quite general. Deletion of SIR4 enhanced mURA3 and MET15 silencing, but deletion of SIR1 or SIR3 did not affect silencing, indicating that the mechanism of silencing differs from that at telomeres and silent mating loci. Deletion of SIR2 resulted in increased psoralen cross-linking of the rDNA in vivo, suggesting that a specific chromatin structure in rDNA down-regulates polymerase II promoters.
\end{abstract}

[Key Words: Transcriptional repression; S. cerevisiae; silent mating loci; SIR genes; yeast ribosomal DNA]

Received October 4, 1996; revised version accepted December 2, 1996.

Chromatin structure can influence gene expression both positively and negatively (for review, see Kingston et al. 1996). Negative influence over a large region of DNA in the budding yeast Saccharomyces cerevisiae is called transcriptional silencing and is known to occur at the silent mating loci and telomeres (Loo and Rine 1994). The chromatin structure associated with these regions is probably analogous to the cytologically defined heterochromatin of more complex eukaryotes such as Drosophila (Hecht et al. 1995; Braunstein et al. 1996). Similarities between silenced regions and heterochromatin include condensed chromatin structure, replication late in $S$ phase, perinuclear location, and epigenetic repression of gene activity (Thompson et al. 1994). Little effort has been directed toward defining additional silenced regions in the yeast genome.

Silenced regions such as telomeres often have repetitive DNA sequences. The most repetitive yeast DNA sequence is the ribosomal DNA (rDNA). The S. cerevisiae rDNA consists of a tandem array of $9.1 \mathrm{~kb}$ units repeated 100-200 times on chromosome XII (Petes and Botstein 1977; Philippsen et al. 1978) and is localized in the nucleolus, which, like telomeres, lies in apposition to the nuclear envelope. Each repeat contains a $5 \mathrm{~S}$ rRNA gene transcribed by RNA polymerase III (Pol III) and a 35S pre-rRNA gene transcribed by RNA Pol I. Repeated DNA in the genome is subject to recombination, and for essential genes such as the rDNA, excessive recombina- tion could be deleterious. Regulation of such recombination is therefore likely to be a critical process. How rDNA mitotic and meiotic recombination is repressed is unclear, but this suppression requires the silencing gene, SIR2 (Gottlieb and Esposito 1989).

SIR2, along with SIR3, SIR4, RAP1, and histones $\mathrm{H} 3$ and $\mathrm{H} 4$, are proteins required for silencing at the $H M$ loci and telomeres in S. cerevisiae (Loo and Rine 1995). Telomeric silencing, also called telomere position effect (TPE), originates at the telomere and "spreads" $3-5 \mathrm{~kb}$ toward the centromere, such that genes introduced near chromosome ends are silenced progressively less strongly with distance from the telomere (Gottschling et al. 1990). SIR1 is necessary for establishment, but not maintenance of $H M$ locus silencing (Pillus and Rine 1989), and is not required for TPE (Aparicio et al. 1991), suggesting there may be different forms of silencing. The role of SIR2 in suppression of rDNA recombination could result from a repressive chromatin structure in rDNA. However, integration of the LEU2, URA3, and $A D E 2$ genes in single copy into rDNA leads to their expression (Szostak and Wu 1980; Keil and McWilliams 1993), indicating that at least some Pol II-transcribed genes can be expressed within rDNA.

Silenced regions have a generally repressive chromatin structure. This is demonstrated by shutdown of pol III transcription (Schnell and Rine 1986) and inaccessibility of $H M$ loci and telomeres to $H O$ endonuclease and DNA methyltransferase in vivo (Strathern et al. 1982; Kostriken et al. 1983; Gottschling 1992; Singh and Klar 
1992) and to restriction endonucleases in isolated yeast nuclei (Loo and Rine 1994).

In vivo psoralen cross-linking has revealed that the chromatin structures of inactive and actively transcribed rDNA gene copies are different (Dammann et al. 1993). Inactive gene copies are packaged in regular nucleosomal arrays, similar to bulk chromatin, whereas active gene copies are nucleosome-free. The nontranscribed spacer (NTS) of inactive rDNA gene copies is also packaged into a regular nucleosomal array, whereas the NTS of active gene copies shows an unusual cross-linking pattern suggestive of a complex structure (Dammann et al. 1993). These studies suggest that rDNA chromatin structure is highly influenced by Pol I transcription. Accordingly, topoisomerases I (TOP1), II (TOP2), and III (TOP3) appear to be important for pol I transcription and/or suppression of rDNA recombination (Brill et al. 1987; Christman et al. 1988; Kim and Wang 1989; Gangloff et al. 1994).

In this paper we describe a novel form of transcriptional silencing in $S$. cerevisiae rDNA. Tyl retrotransposons marked with a modified URA3 gene (mURA3) efficiently integrated into rDNA, targeting primarily upstream of the Pol III-transcribed 5S rRNA gene. This mURA3 marker was found to be silenced. The MET15 and $L E U 2$ genes were also silenced, demonstrating that rDNA silencing is not gene-specific. rDNA silencing depended on SIR2, consistent with the increased accessibility of rDNA to psoralen cross-linking observed in sir2 mutants. Deletion of SIR4 actually enhanced rDNA silencing, but SIR1 and SIR3 deletions did not significantly affect silencing, indicating that rDNA silencing differs from classical silencing. Remarkably, deletion of SIR2 increased the proportion of actively transcribed rDNA gene copies in the tandem array.

\section{Results}

\section{Identification of repressed Ty insertions in the rDNA}

Tyl was marked with a $U R A 3$ gene and placed under control of the GAL1 promoter (Fig. 1A). Galactose induction produced high levels of Tyl-mURA3 transposition, as with other marked elements (Boeke et al. 1985, 1988; Curcio and Garfinkel 1991). Ura ${ }^{-}$parent cells that receive a new chromosomal Tyl-mURA3 element through transposition become $\mathrm{Ura}^{+}$and sensitive to 5-fluoro-orotic acid (FOA) (Boeke et al. 1984). Following transposition induction of strain JS50-2 (Table 1), FOA-resistant $\left(\mathrm{FOA}^{\mathrm{R}}\right)$ colonies were retested for their Ura phenotype, and, as expected, most were Ura- ${ }^{-}$Surprisingly, $\sim 15 \%$ of the $\mathrm{FOA}^{\mathrm{R}}$ colonies were weakly $\mathrm{Ura}^{+}$. Among these, four classes of $\mathrm{Ura}^{+}$growth were observed $(+/-,+,++$, and +++ ; Fig. 1B). No differences in growth were detected on nonselective medium.

A genomic Southern blot of DNA isolated from such $\mathrm{FOA}^{\mathrm{R}} / \mathrm{Ura}^{+}$clones was probed with $U R A 3$ (Fig. 1C). The size of each band represents the distance between the Tyl HindIII site to the first flanking genomic HindIII site, which varies for different integration sites (Boeke et al. 1985). Most of the clones (22 of 27) contained single integration events, and thus the varied repression of $\mathrm{Ura}^{+}$ growth was attributable not to differences in TylmURA3 copy number, but rather to position effects on

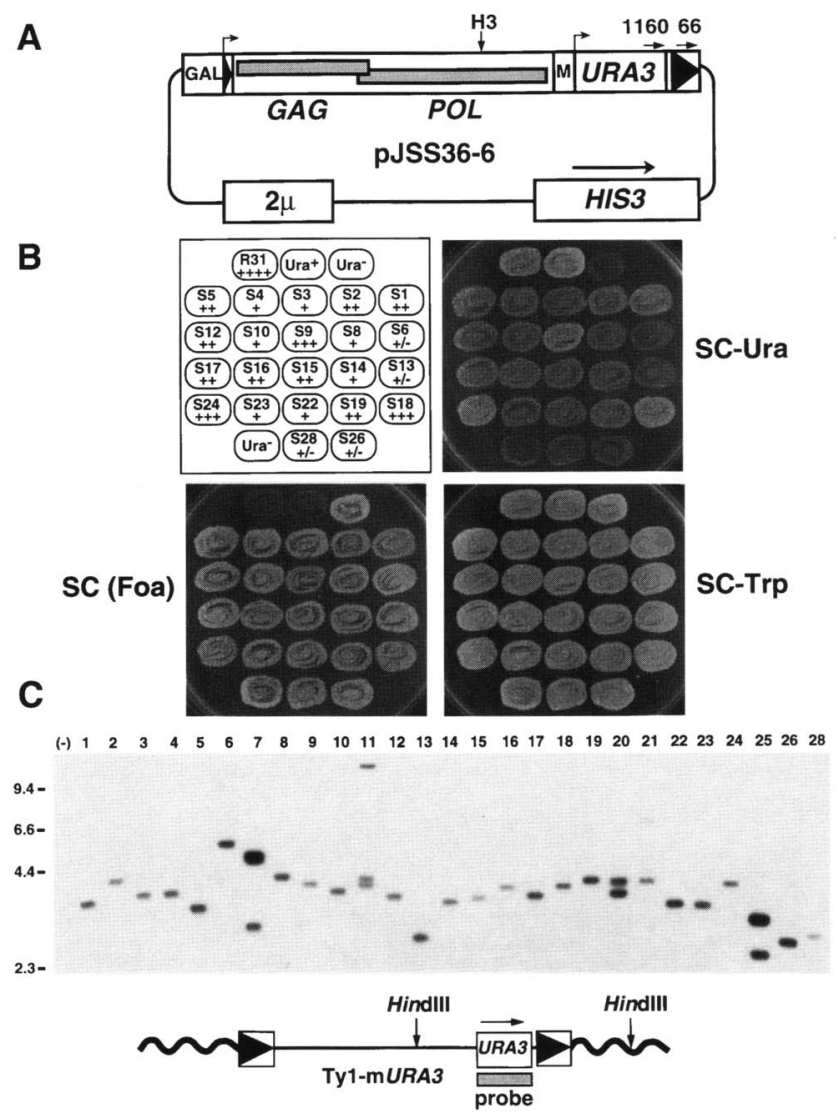

Figure 1. Ty1-mURA3 transposition and isolation of $\mathrm{FOA}^{\mathrm{R}} /$ ura $^{+}\left(\mathrm{Foa}^{\mathrm{R}} / \mathrm{Ura}^{+}\right)$integrants. (A) Structure of the pGAL-Tyl$m U R A 3$ overexpression plasmid pJSS36-6. Ty1 is marked with the $U R A 3$ open reading frame (ORF) driven by a minimal TRP1 promoter (M). Tyl is fused to the GAL1 promoter. The directions of Tyl and $m U R A 3$ transcription are depicted by the bent arrows. The HindIII site in the Tyl-mURA3 sequence is indicated $(\mathrm{H} 3)$. The sites for primers JB1160 and JB66 are shown (horizontal arrows); $G A G$ and $P O L$ are Tyl protein coding genes. (B) $\mathrm{FOA}^{\mathrm{R}} / \mathrm{Ura}^{+}$colonies isolated after Ty1-mURA3 transposition induction containing single Tyl-mURA3 insertions were patched on YPD, replica-plated to SC-Ura, nonselective SC-Trp, and SC (FOA) plates, and grown $21 \mathrm{hr}$ at $30^{\circ} \mathrm{C}$; $\mathrm{Ura}^{-}$control is parental strain JB740, $\mathrm{URA}^{+}$strain is JS93. R31 is a random $\mathrm{Ura}^{+} / \mathrm{FOA}^{\mathrm{s}}$ isolate that contains a single non-rDNA Ty1-mURA3 insertion. Levels of growth on SC-Ura compared with R31 are indicated as $+/-,+,++$, or $+++|C|$ Genomic blot analysis of $\mathrm{FOA}^{\mathrm{R}} / \mathrm{Ura}^{+}$Tyl-mURA3 insertions. HindIII-digested genomic DNA fragments were separated on $0.7 \%$ agarose, transferred to GeneScreen Plus, and hybridized with a $U R A 3$ probe (bottom diagram) that recognizes HindIII fragments containing the $3^{\prime}$ end of Tyl-mURA3. Each band represents a single Tyl-mURA3 insertion. The Ura ${ }^{-}$control $(-)$is parent strain JB740; $M_{r}$ markers ( $\mathrm{kb}$, left), and isolate numbers (top) are indicated. Chromosomal DNA is represented by thick wavy lines. 
Table 1. Yeast strains

\begin{tabular}{|c|c|c|}
\hline Strain & Genotype & Parent \\
\hline $\mathrm{BY} 384^{\mathrm{a}}$ & 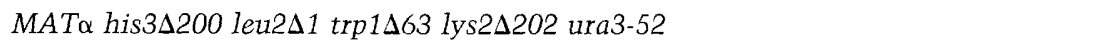 & - \\
\hline GRF167 & MAT $\alpha$ his $3 \Delta 200$ ura3-167 & - \\
\hline $\mathrm{JB} 740$ & 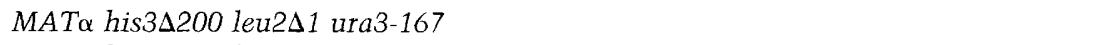 & GRF167 \\
\hline JS92 & 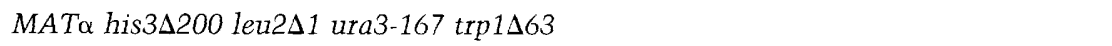 & $\mathrm{JB} 740$ \\
\hline JS93 & 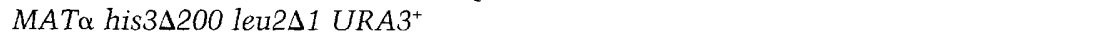 & $\mathrm{JB} 740$ \\
\hline JS207 & 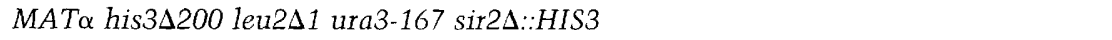 & $\mathrm{JB} 740$ \\
\hline IS209 & 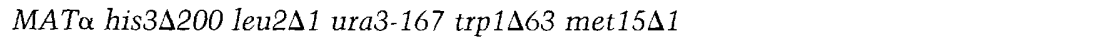 & JS92 \\
\hline JS50-2 & MATo his $3 \Delta 200$ leu $2 \Delta 1$ ura3-167 pJSS36-6 & JB740 \\
\hline $\mathrm{S} 1 \rightarrow \mathrm{S} 28^{\mathrm{c}}$ & 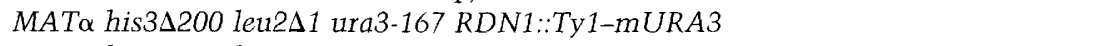 & IS50-2 \\
\hline $\mathrm{R} 31^{\mathrm{d}}$ & 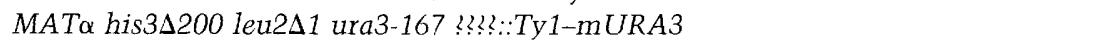 & JS50-2 \\
\hline JS210 & 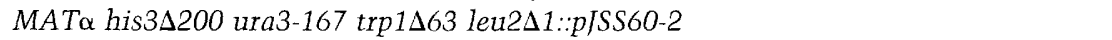 & JS92 \\
\hline JS215 & 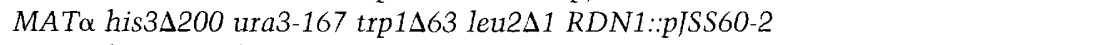 & JS92 \\
\hline JS216 & 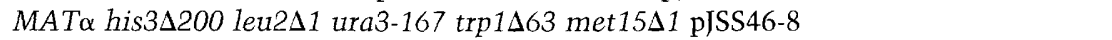 & JS209 \\
\hline$M 1^{\mathrm{c}}$ & 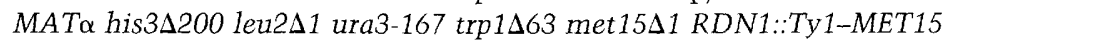 & JS216 \\
\hline JS218 & 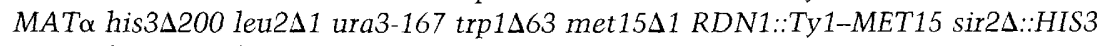 & M1 \\
\hline JS219 & 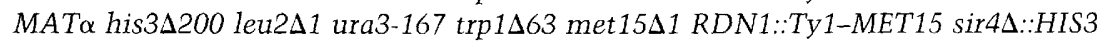 & M1 \\
\hline IS220 & 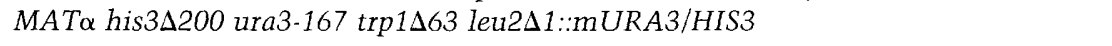 & JS92 \\
\hline
\end{tabular}

${ }^{\mathrm{a}}$ From Winston et al. (1995).

${ }^{\text {b}}$ From Boeke et al. (1985).

'Ty1-mURA3 insertions at various locations of the rDNA.

${ }^{\mathrm{d}}$ Ty $1-m U R A 3$ insertion at an unknown non-rDNA locus.

'Ty1-MET15 insertion upstream of the 5S rDNA.

mURA3 expression. Most of the bands clustered between 3 and $4 \mathrm{~kb}$ in size, suggesting that the $\mathrm{FOA}^{\mathrm{R}} / \mathrm{Ura}^{+}$ Ty $1-m U R A 3$ insertions might be in a common genomic region. DNAs from three isolates were cloned and sequenced. Each element had inserted into rDNA in or near the nontranscribed spacer (Fig. 2A).

Based on the locations of these integration sites, oligonucleotide primers were designed to detect rDNA Tyl-mURA3 integration events in each $\mathrm{FOA}^{\mathrm{R}} / \mathrm{Ura}^{+}$isolate shown in Figure 1B, using a colony PCR assay. The insertion sites were inferred from PCR product size and confirmed by detailed Southern blot mapping. Most insertions clustered within a 600-bp window upstream of the $5 S$ rRNA gene with Ty1-mURA3 integrating in both orientations (Fig 2A).

Using plasmid targets in vivo, Tyl integration has been shown to target upstream of genes transcribed by Pol III, including the 5S rRNA gene (Devine and Boeke 1996). Because the rDNA tandem array contains 100-200 copies of the 5S rRNA gene, it could be a highly preferred site of integration. To determine whether the rDNA region is an over- or under-represented target, 40 random $\mathrm{Ura}^{+}$isolates were collected following transposition induction and the locations of the rDNA insertions determined as above. Most of the $40 \mathrm{Ura}^{+}$isolates contained more than one Tyl-mURA3 insertion, and of 133 total insertions found in these 40 strains, $19(14.3 \%)$ were rDNA-specific. Minimum estimates for the frequency of Tyl integration into rDNA compared with other regions of the genome were then calculated (Table 2). The rDNA was approximately equivalent to the rest of the genome in terms of overall targeting frequency. However, because of its repetitiveness, a relatively large percentage of the total genomic Tyl integration events occurred within rDNA.

To quantitatively determine the differences in $\mathrm{Ura}^{+}$ growth between various Ty1-mURA3-rDNA and nonrDNA isolates, growth curves of isolates S2, S3, S6, S9, and S26 in SC-Ura medium were performed (Fig. 2B). Control isolate $\mathrm{R} 31$ contains a single Ty1-mURA3 insertion that is outside the rDNA and, like other nonrDNA insertions, is completely FOA-sensitive $\left(\mathrm{FOA}^{\mathrm{s}}\right)$. It serves as a control for the strength of the minimal TRP1 promoter used to drive mURA3 expression (Fig. 1A). The $U R A 3^{+}$strain (JS93) grew approximately three times faster than R31, demonstrating the reduced activity of the mURA3 promoter. Growth rates of the rDNA isolates tested ranged from $\sim 4$-fold $\left(\mathrm{S} 9_{+++}\right)$to 38 -fold $(\mathrm{S} 6+/-)$ slower than R31.

Ability to grow on both SC-Ura and FOA selection media is unusual. In S. cerevisiae, this phenotype is observed when URA3 is placed adjacent to telomeres (Gottschling et al. 1990); a percentage of cells in the population are $\mathrm{FOA}^{\mathrm{R}}$, representing those in which URA3 is completely silenced. To determine whether a similar phenomenon was occurring in rDNA, the efficiency of plating on SC-Ura and FOA media was tested for selected Ty1-mURA3 insertions (Table 3). For rDNA insertions, up to $100 \%$ of the cells were $\mathrm{FOA}^{\mathrm{R}}$, even though close to $100 \%$ of the cells also produced $\mathrm{Ura}^{+}$ colonies after extended incubation. Good $\mathrm{Ura}^{+}$growth phenotypes correlated with lower percentages of FOA $^{R}$ cells in the population. These results are consistent with each isolate having an intermediate level of $m U R A 3$ expression that is not above the threshold of expression to produce FOA sensitivity. Interestingly, the colony sizes 
Figure 2. Targeting of Ty-1-mURA3 integration to rDNA. (A) Organization of the $S$. cerevisiae 9.1-kb rDNA repeat, embedded within a tandem array. The 5S rRNA gene is represented by $5 \mathrm{~S}$. The $18 \mathrm{~S}, 5.8 \mathrm{~S}$, and $25 \mathrm{~S}$ rRNAs are processed from the $35 \mathrm{~S}$ precursor RNA. The NTS between the $25 \mathrm{~S}$ of one repeat and $18 \mathrm{~S}$ of another repeat is interrupted by a $5 \mathrm{~S}$ gene. Locations of PCR primers used for detection of Tyl insertions within rDNA are indicated horizontal arrows). Integration sites and orientations of Tyl-mURA3 insertions (Fig. 1B) are shown as vertical arrows (inset). Orientations of TylmURA3 insertions relative to the rDNA sequence are shown for each arrow direction. The three ARS near-consensus elements in nontranscribed spacer 2 (NTS2) are shown as solid circles. Thin bent arrows represent $5 \mathrm{~S}$ and $35 \mathrm{~S}$ transcription start sites. Nucleotide scale for the inset is based on EMBL accession no. X00486 (Skryabin et al. 1984); HindIII sites are indicated $(\mathrm{H})$. (B) Growth of rDNA insertion isolates was measured in liquid SC-Ura medium. Overnight YPD cultures were pelleted, washed with $\mathrm{H}_{2} \mathrm{O}$, diluted to $\mathrm{A}_{600}$ of 0.1 in $\mathrm{SC}-\mathrm{Ura}$, and growth monitored over time. Symbols for each strain are indicated, listed in descending order of $\mathrm{Ura}^{+}$ growth.

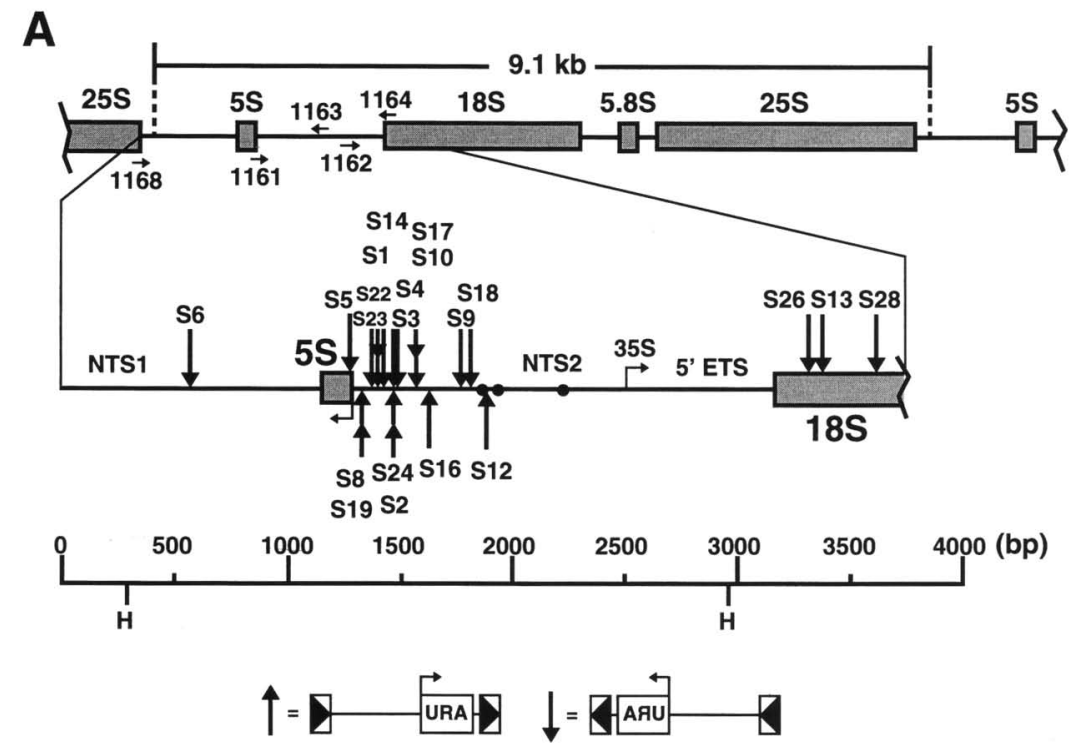

B

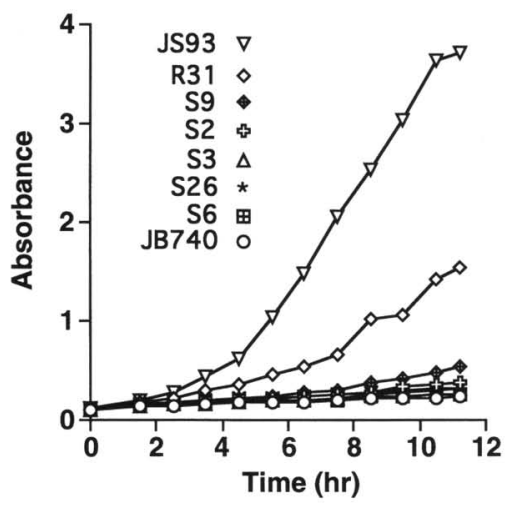

the rDNA and the promoter, making differences in expression between isolates difficult to interpret.

It has been proposed that TPE is a result of the continuous spreading of a heterochromatin-like structure outward from the telomere toward the centromere (Renauld et al. 1993; Hecht et al. 1995). To determine whether there is a similar gradient of silencing in the rDNA, a dual-marker silencing reporter lacking Tyl sequences was developed that can be integrated at any position within the rDNA sequence by transformation of a mURA3-HIS3 PCR product with 39 nucleotides of predetermined rDNA sequence at each end. MURA3 and HIS 3 are adjacent to each other and in tandem, with HIS 3 transcription directed away from $m U R A 3$ (Fig. 3A). HIS3 is not noticeably repressed within the rDNA, which allows for selection of $\mathrm{His}^{+}$transformants containing the reporter without bias. The reporter was integrated in both orientations at four locations within the rDNA: NTS1, NTS2, $5^{\prime}$ end of 18 S, and in the middle of the 25S (Fig. 3A). The levels of $\mathrm{Ura}^{+}$growth for each integration site shown in Figure 3A and in both possible orientations were approximately equal $(+\mid-)$, consistent 
Table 2. Ty1 rDNA integration targeting frequency

\begin{tabular}{|c|c|c|c|}
\hline $\begin{array}{l}\text { Assumed } \\
\text { number of } \\
\text { rDNA units }\end{array}$ & $\begin{array}{l}\text { rDNA } \\
\text { cluster } \\
\text { size }(\mathrm{kb})^{\mathrm{a}}\end{array}$ & $\begin{array}{l}\text { rDNA targeting } \\
\text { frequency } \\
\text { (insertions } / \mathrm{kb})^{\mathrm{b}}\end{array}$ & $\begin{array}{l}\text { Non-rDNA } \\
\text { targeting } \\
\text { frequency } \\
{\text { (insertions } / \mathrm{kb})^{\mathrm{c}}}\end{array}$ \\
\hline 100 & 910 & $2.08 \times 10^{-2}$ & $0.94 \times 10^{-2}$ \\
\hline 150 & 1365 & $1.39 \times 10^{-2}$ & $0.94 \times 10^{-2}$ \\
\hline 163 & $1485^{\mathrm{d}}$ & $1.28 \times 10^{-2}$ & $0.94 \times 10^{-2}$ \\
\hline 200 & 1820 & $1.04 \times 10^{-2}$ & $0.94 \times 10^{-2}$ \\
\hline
\end{tabular}

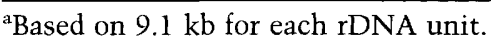

${ }^{b}$ Nineteen rDNA insertions were detected in a total of 133 integration events from $40 \mathrm{Ura}^{+}$colonies, using each primer shown in Fig. 2A, in combination with JB1160. In the population of cells studied, $50 \%$ were $\mathrm{Ura}^{+}$.

${ }^{\mathrm{C}}$ The remaining $114 \mathrm{Ty} 1-\mathrm{mURA3}$ insertions were not detected within the NTS and are assumed to be outside the rDNA, assuming non-rDNA consists of $12,500 \mathrm{~kb}$.

${ }^{\mathrm{d}}$ Size of rDNA in the strain S288C (Rustchenko and Sherman 1994).

with silencing of the mURA3 marker throughout the rDNA repeat sequence (Fig. $3 \mathrm{~B}$ ). Each transformant was also $\mathrm{FOA}^{\mathrm{R}}$, as was observed for the Tyl-mURA3 insertions. However, when the dual-marker reporter was integrated at the non-rDNA locus $L E U 2$, Ura ${ }^{+}$growth was strong and fully sensitive to FOA, as observed previously for R31. Selection for both markers simultaneously did not increase $\mathrm{Ura}^{+}$growth (data not shown), indicating that HIS 3 transcription does not affect $m U R A 3$ silencing. Thus the observed $m U R A 3$ silencing does not require cis-acting sequences within Ty1.

\section{rDNA-mediated repression occurs only within the tandem array}

It was possible that cis-acting sequences in the rDNA could simply be negatively affecting mURA3 expression

Table 3. Efficiency of plating

\begin{tabular}{llcc}
\hline Strain & $\begin{array}{l}\text { Ura } \\
\text { phenotype }\end{array}$ & SC-Ura & SC (FOA) \\
\hline JB740 & - & 0.00 & 1.10 \\
R31 & ++++ & 1.04 & 0.00 \\
S2 & ++ & 0.99 & 0.67 \\
S3 & + & 0.93 & 0.82 \\
S26 & $+1-$ & 0.01 & 0.91 \\
S6 & + - & 0.04 & 1.09 \\
\hline
\end{tabular}

${ }^{\mathrm{a} S t r a i n s}$ were grown as patches for $24 \mathrm{hr}$ at $30^{\circ} \mathrm{C}$ on a YPD plate. The patches were scraped from the plate and diluted in sterile water. Two hundred microliters ( 150-200 cells) was spread on three plates each of SC-Trp glucose, SC-Ura glucose, and SC (FOA) glucose. All visible colonies were counted after 4 days growth. Efficiency of plating was calculated as the number of SC-Ura or SC (FOA) colonies divided by the number of SC-Trp colonies.

${ }^{\mathrm{b}}$ Additional small colonies will eventually grow for strains S3, S6, and S26 on SC-Ura plates after incubations $>4$ days.
A

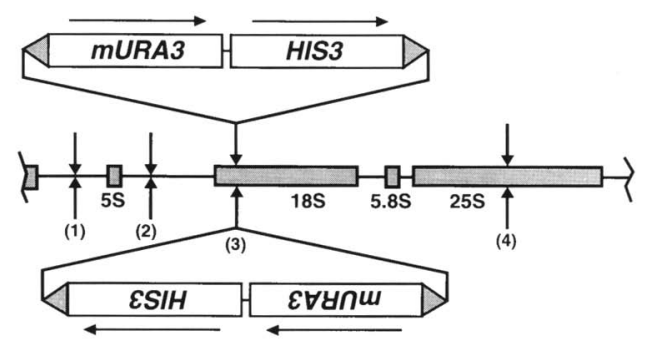

B

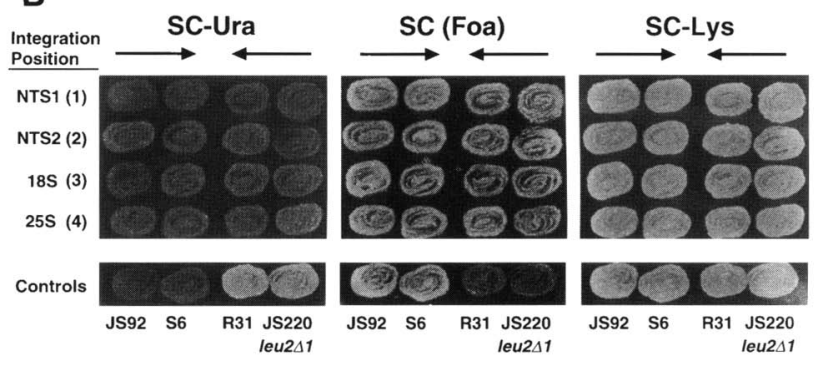

Figure 3. Tyl-independent rDNA silencing of mURA3. (A) Schematic diagram of mURA3-HIS3 dual marker reporter, generated as a PCR cassette with adjacent rDNA sequences (shaded triangles). Using eight different sets of primers, the cassette was integrated at four different rDNA sequences in both orientations by transformation into JS92 and selection for $\mathrm{His}^{+}$colonies. Integration locations were confirmed by colony PCR as described for Ty1-mURA3 integration events. Vertical arrows indicate integration sites, represented as $1,2,3$, and 4 . The diagram is not to scale. $(B)$ Comparison of $\mathrm{Ura}^{+}$growth at each rDNA position. Two transformants at each location were patched onto YPD medium and grown $24 \mathrm{hr}$ at $30^{\circ} \mathrm{C}$. This plate was replica-plated to $\mathrm{SC}-\mathrm{Ura}, \mathrm{SC}+\mathrm{FOA}$, and nonselective $\mathrm{SC}-$ Lys plates and grown $21 \mathrm{hr}$ at $30^{\circ} \mathrm{C}$. Transcriptional direction of each cassette (top) and positions of insertion (left $)$ are indicated. Controls are indicated.

locally, rather than silencing being mediated globally by the rDNA array. If this were the case, similar repression would occur if an rDNA gene copy containing the mURA3 marker was positioned elsewhere in the genome, outside of the array. A LEU2-integrating vector (pISS60-2) was constructed that contains a single $9.1-\mathrm{kb}$ rDNA gene copy with $m U R A 3$ inserted in the $25 \mathrm{~S}$ region (Fig. 4A). The entire rDNA::Ty $1-m U R A 3$ construct was integrated at the leu2 $\Delta 1$ locus or into the rDNA tandem array to compare the levels of mURA3 expression at each location (Fig. 4B). When targeted to leu2 $\Delta 1$, all transformants were completely $\mathrm{Ura}^{+}$and $\mathrm{FOA}^{\mathrm{s}}$, indicating there are no cis-acting sequences within a single rDNA gene copy that can silence mURA3 when located outside the tandem array. In contrast, when targeted into the rDNA array, mURA3 was silenced as expected. Surprisingly, even the LEU2 gene of pISS60-2 was also partially silenced as judged by reduced colony size on SC-Leu medium when targeted to rDNA (Fig. 4B). Silencing of LEU2 was unexpected because it was integrated into rDNA previously without any report of repression (Szostak and $\mathrm{Wu}$ 1980). We conclude that 


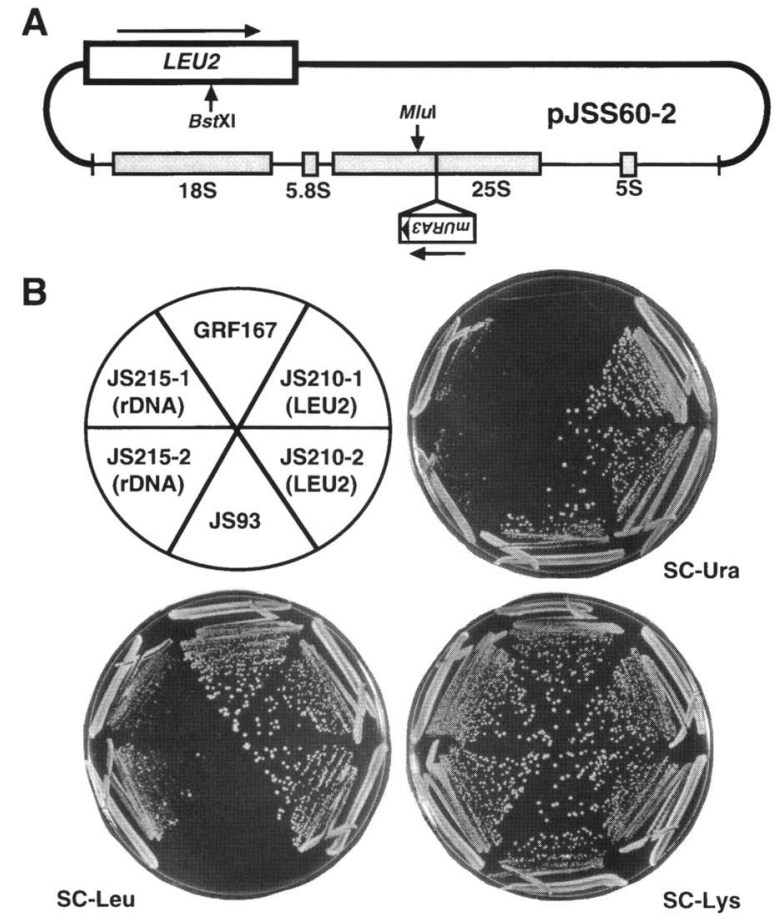

Figure 4. Integration of a single rDNA::mURA3 unit outside the tandem array. (A) Schematic of plasmid pJSS60-2, which contains a single rDNA unit with mURA3 inserted in the $25 \mathrm{~S}$ region. Transformation of BstXI-linearized plasmid into JS92 results in integration of the plasmid to leu $2 \Delta 1$ (JS210-1,2); transformation of MluI-linearized plasmid results in integration in the rDNA tandem array (JS215-1,2). The $5^{\prime}$ end of this repeat unit is downstream of the Pol I transcriptional start site. The Tyl 3' LTR is used as the terminator for mURA3 transcription. (Thick lines) Plasmid sequences; (thin lines) rDNA sequences. The diagram is not to scale. $|B|$ Two transformants at each locus were streaked out for single colonies on either SC-Ura, SC-Leu, or nonselective SC-Lys plates and incubated for 2 days at $30^{\circ} \mathrm{C}$. GRF167 and JS93 are $L E U 2^{+}$and $U R A 3^{+}$controls, respectively. Strain numbers are indicated at top left, along with the integration site.

rDNA-mediated silencing is specific to the tandem array and, furthermore, is not restricted to mURA3.

\section{SIR2 is required for silencing of mURA3 in rDNA}

To determine whether the $S I R$ genes were required for silencing of mURA3 in the rDNA, we deleted SIR1, SIR2, SIR3, or SIR4 from the Ty1-mURA3 isolates S2, S3, and S6. Deletion of SIR1, SIR3, or SIR4 did not increase $\mathrm{Ura}^{+}$growth, indicating that these genes are not required for silencing of mURA3 (Fig. 5A). However, a sir4 mutant appeared to reduce the $\mathrm{Ura}^{+}$growth of isolate S2. The sir2 mutants resulted in a dramatic increase in $\mathrm{Ura}^{+}$growth (Fig. 5A). The increased growth was comparable to that observed for control non-rDNA isolate R31. Because of the increased levels of mitotic unequal crossing-over within rDNA in sir2 mutants (Gottlieb and Esposito 1989), it was possible that the increased

$\mathrm{Ura}^{+}$growth rate resulting from a sir2 mutation was caused by amplification of the mURA3 marker rather than derepression of silencing. If this were the case, then the $\mathrm{Ura}^{+}$growth increase would not be reversed by reintroduction of $S I R 2^{+}$back into the sir2 mutant. To test this, we transformed the sir2 mutant strains with a SIR2

A

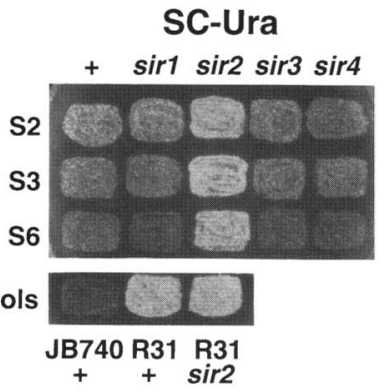

B
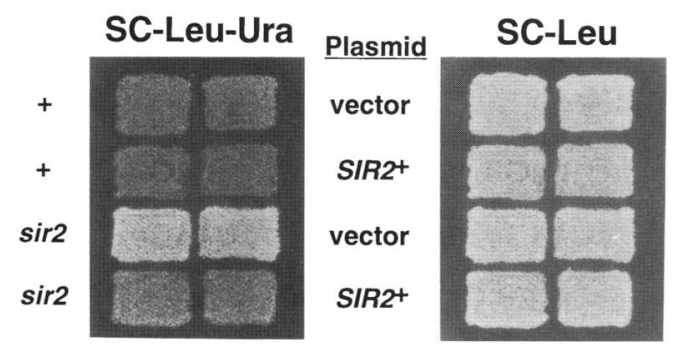

C

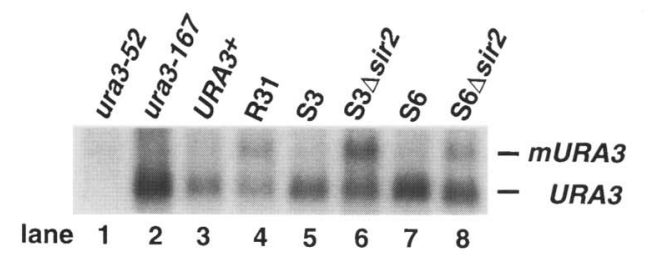

Figure 5. Effect of $S I R$ gene deletions on rDNA silencing of Ty1-mURA3 insertions. (A) The four individual SIR genes were deleted from Ty1-mURA3 isolates $\mathrm{S} 2, \mathrm{~S} 3$, and $\mathrm{S} 6$ by replacement with HIS3. Parental insertion strains are indicated $(+)$. $\operatorname{sir} 1 \Delta:: H I S 3, \operatorname{sir} 2 \Delta:: H I S 3, \operatorname{sir} 3 \Delta:: H I S 3$, or $\operatorname{sir} 4 \Delta:: H I S 3$ strains were patched on YPD plates, replica-plated to SC-Ura and nonselective SC-Trp plates, and grown for $20 \mathrm{hr}$. Controls are JB740 (ura3-167), R31 (non-rDNA insertion), and sir2 $2:: H I S 3$ in the R31 background. Controls were grown on the same plates as S2, S3, and S6. $(B)$ The S6 and S6 6 sir2 strains shown in $A$ were transformed with either control vector pRS415 or a SIR2 CEN plasmid (pCAR237). SIR2 genotype is indicated. Two independent transformants for each combination were patched onto a SC-Leu plate and grown for $24 \mathrm{hr}$ at $30^{\circ} \mathrm{C}$, followed by replicaplating to SC-Leu-Ura and SC-Leu. Photos were taken after 20 hr growth at $30^{\circ} \mathrm{C}$. Ura ${ }^{+}$growth is indicated on the SC-Leu-Ura plates. $(C)$ RNA blot analysis of mURA3 transcriptional silencing. Total RNA isolated from strains BY384 (ura3-52; lane 1), JB740 (ura3-167; lane 2), IS93 (URA3 ${ }^{+}$; lane 3), R31 (lane 4), S3 (lane 5), S3 $\Delta$ sir2 (lane 6), S6 (lane 7), and S6 $\Delta$ sir2 (lane 8) was separated on formaldehyde-containing $1.2 \%$ agarose, transferred to GeneScreen Plus, and hybridized with an antisense $3^{\prime}$ $U R A 3$ probe. The ura3-167 and URA $3^{+}$messages are the same size and their locations are indicated by URA3. The location of the mURA3 message is also indicated. 
plasmid. As shown in Figure 5B for S6, the SIR2 plasmid reversed the phenotype of the $\mathrm{S} 6$ sir2 mutant to the silenced state, whereas an empty vector did not. Subsequent loss of the SIR2 plasmid resulted in a further reversal in phenotype to the expressed state. Amplification of $m U R A 3$ was also ruled out by a quantitative Southern blot, which showed that the copy number of $m U R A 3$ in the sir2 mutant population of $\mathrm{S} 6$ had not significantly increased over that of the SIR2 parent population. We therefore conclude that the effect of the sir2 mutation on the expression of $m U R A 3$ does not result from recombinational amplification.

\section{mURA3 silencing is transcriptional}

The effect of a sir2 deletion on $m U R A 3$ expression levels for rDNA insertions S3 and S6 was tested directly by RNA blot analysis. The $\sim 1$-kb endogenous URA3 transcript is present in the ura3-167 background and provides a convenient RNA-loading control for RNA blots (Fig. 5C, lane 2). The mURA3 transcript produced by Tyl-mURA3 is terminated by the Ty1 $3^{\prime}$ long terminal repeat (LTR) and is expected to be $\sim 1165$ nucleotides long before polyadenylation. Non-rDNA insertion R31 produced a $m U R A 3$ transcript of about that size (Fig. 5C, lane 4). In contrast, this $m U R A 3$ transcript was undetectable in rDNA isolates S3 and S6 (lanes 5 and 7, respectively). Deletion of SIR2 in S3 and S6 resulted in the appearance of $m U R A 3$ RNA (lanes 6 and 8, respectively). These results directly demonstrate the transcriptional inactivity of $m U R A 3$ within the rDNA, and the requirement of SIR2 for this silencing.

\section{A colony-color assay for analyzing rDNA-mediated silencing}

Transcriptional silencing of $A D E 2$ placed near telomeres results in reversible switching between on and off states of expression that produces easily visible red and white sectors in colonies (Gottschling et al. 1990). To determine whether switching occurs in rDNA-mediated silencing, a colony-color assay based on the MET15 gene was adapted for use in the rDNA. Growth of met $15 \mathrm{mu}$ tant yeast strains on $\mathrm{Pb}^{2+}$-containing medium results in dark brown colonies, whereas colonies of MET15 strains remain white (Ono et al. 1991; Cost and Boeke 1996). MET15 was introduced into the rDNA by $5 \mathrm{~S}$ rDNA-targeted transposition of a MET15-marked Tyl (Fig. 6A). Random insertions of Ty1-MET15 into nonrDNA genomic regions resulted in white colonies on $\mathrm{Pb}$ medium (isolate M9), indicating that Tyl-MET15 can fully complement a met15 deletion in single copy (Fig. 6B). However, Tyl-MET15 insertions into rDNA resulted in colonies with an intermediate tan color (isolate M1), indicating that MET15 is also silenced in the rDNA. The darkness of the tan color varied among different Ty1-MET15 rDNA isolates and intensified with time for all isolates (data not shown). Occasional dark brown sectors were observed, but these represented recombination events in the colony leading to permanent loss of

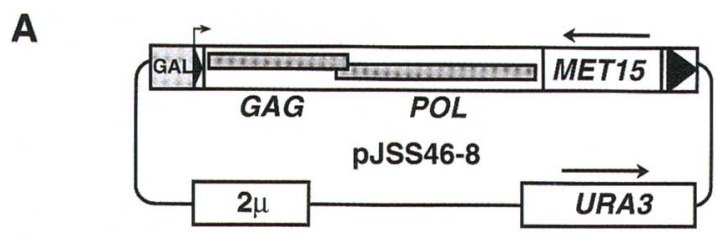

B

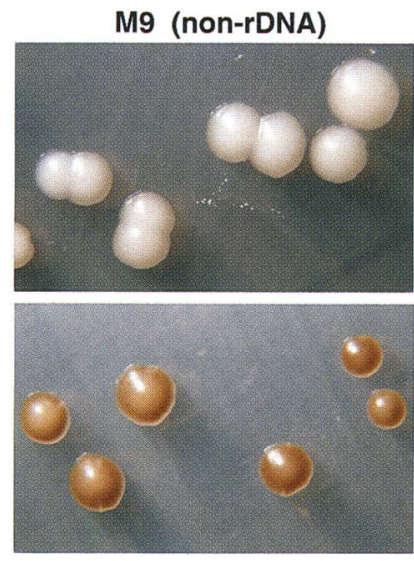

M1 sir4A::HIS3

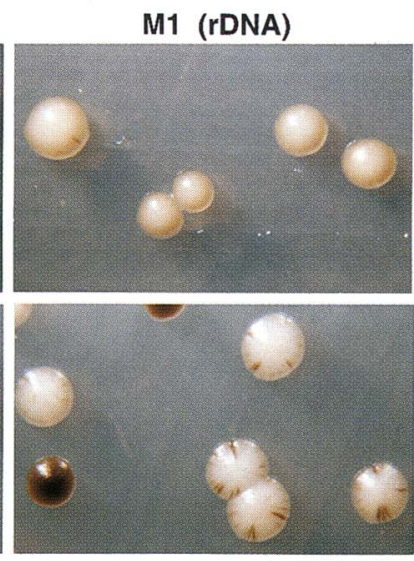

M1 sir2A::HIS3
Figure 6. Colony color assay for rDNA silencing. $(A)$ Schematic diagram of GAL1-Ty1-MET15 vector pJSS46-8. Ty1 is marked at the 3 ' end with MET15 in the reverse orientation. $M E T 15$ expression is driven by its own promoter. (B) SIR2 or SIR4 were replaced with HIS3 in Tyl-MET15 rDNA isolate M1. The parent (M1) and its sir2 and sir4 deletions were streaked for single colonies onto $\mathrm{Pb}$-containing rich medium and incubated for 5 days at $30^{\circ} \mathrm{C}$, when photos were taken at $6 \times$ magnification. Strain M9 is a non-rDNA Tyl-MET15 insertion used as a Met ${ }^{+}$ control that produces white colonies. The uniform dark brown color of $\mathrm{Met}^{-}$colonies can be seen in the sir2 mutant. These colonies originated from single cells that had already lost MET15 through recombination at the time of plating.

MET15, not reversible switching (data not shown). The frequency of these dark brown sectors dramatically increased and the background colony color turned white when sir2 was deleted (Fig. 6B), indicating loss of silencing and increased recombination. The intermediate color phenotype of rDNA::Tyl-MET15 insertions differs from that observed for telomeric silencing, in which switching results in either white or red sectors but not an intermediate pink color (Gottschling et al. 1990).

The only SIR gene deletion that eliminated $m U R A 3$ silencing in Figure 5A was sir24::HIS3. To determine whether deletion of any of the other SIR genes might enhance silencing, SIR1, SIR3, or SIR4 were deleted in isolate M1, and assayed for colony color. Deletion of SIR4 greatly enhanced silencing, as measured by a significantly darkened colony color (Fig. 6B), and confirmed initial observations with the Tyl-mURA3 insertions. Deletion of SIR1 or SIR3 had little if any affect on silencing strength (data not shown). This result suggests that Sir4 $p$ is involved in the regulation of rDNA silencing. Two of the known SIR genes have now been implicated in rDNA silencing, although sir4 mutations have 
opposite phenotypes in the rDNA as compared with $H M$ loci and telomeres.

\section{rDNA chromatin structure depends on SIR2}

Silencing of Pol II transcripts in the rDNA could result from a repressive chromatin structure. Inactive and active rDNA gene copies in a yeast cell population can be differentiated by their different chromatin structures and accessibility to UV cross-linking by psoralen (Dammann et al. 1993). These differences are visualized by separation on agarose gels; the more heavily cross-linked DNA migrates more slowly. Actively transcribed gene copies lack nucleosomes and are therefore more accessible to psoralen, and migrate more slowly (Dammann et al. 1993). If SIR2 was responsible for a repressive rDNA structure, deletion of SIR2 should make rDNA chromatin more accessible to psoralen cross-linking, resulting in even slower migration.

Log-phase cultures of JB740 $\left(S I R 2^{+}\right)$and JS207 (sir2 $\Delta:: H I S 3$ ) were photoreacted with psoralen. EcoRI-digested genomic DNA was then separated on agarose and hybridized with probe $\mathrm{B}$ (35S-specific), which detects 1.9and $2.8-\mathrm{kb} 35 \mathrm{~S}$ fragments from non-cross-linked samples (Fig. 7A, lanes 1,2). Cross-linking shifted these into two separate bands, inactive gene copies (f) and actively transcribed gene copies (s). Deletion of SIR2 caused the inactive (f) band to supershift to an even slower migration, indicating that this subset of rDNA copies became more accessible to psoralen. Supershifting of the actively transcribed ( $\mathrm{s}$ ) band was minimal. Supershifting of the NTS species detected by probe A (NTS-specific) in the sir2 mutant was even more dramatic, indicating that the
NTS is affected by Sir2p more than the transcribed region. The non-rDNA 1.5-kb TRP1 fragment did not display any sir2-dependent supershift, indicating specificity for rDNA. Remarkably, the ratio of active and inactive rDNA gene copies was also different in the $S I R 2^{+}$and sir2 strains in log phase cultures. Loss of Sir2p function increased the ratio of actively transcribed to inactive gene copies from 40:60 to 50:50 on average (Fig. 7B), suggesting that SIR 2 and the silencing it mediates may also influence pol I transcription. We conclude that rDNA chromatin is more accessible to psoralen cross-linking when Sir2p function is lost, consistent with the loss of a chromatin structure required for transcriptional silencing.

\section{Discussion}

Transcriptional repression within rDNA is surprising, because transcription by Pol I and Pol III occurs efficiently at this locus. These RNA polymerases normally act within rDNA, whereas Pol II does not. However, Pol II is clearly present in the nucleolus, as several Pol IIdriven genes such as native $U R A 3$ and $A D E 2$ are expressed when inserted into rDNA (Keil and McWilliams 1993), raising the question of how and why mURA3, MET15, and LEU2 are silenced. Several lines of evidence from this study support the hypothesis that the transcriptional repression we observe in rDNA is actually a novel form of silencing. (1) Three out of four genes we inserted into the rDNA were repressed, indicating a nongene-specific mechanism. (2) Repression depends on the silent information regulator gene, SIR2, which is also required for other forms of transcriptional silencing. (3)

Figure 7. The rDNA is more accessible to psoralen cross-linking in the absence of SIR2. $(A)$ EcoRI-digested DNA from either noncrosslinked cells (lanes 1,2) or cross-linked cells (lanes 3-6) were separated on $1.3 \%$ agarose, transferred to GeneScreen Plus, and hybridized with either a $35 \mathrm{~S}$-specific probe in the top panel, an NTS-specific probe in the middle panel, or a TRP1-specific probe in the bottom panel. The SIR2 genotype is indicated at the top; lane numbers are at the bottom. For the 35S-probed panel, slow (s) and fast $(\mathrm{f})$ migrating cross-linked bands are indicated. Non-cross-linked fragment sizes are indicated to the left. JB740 is the SIR2 ${ }^{+}$strain, and JS207 is the sir2 strain. DNA from the crosslinked cells was loaded in duplicate. Each panel represents the same filter stripped and rehybridized. $(B)$ The ratio of actively transcribed gene copies (s bands) to inactively transcribed gene copies ( $\mathrm{f}$ bands) of the above experiment was determined by PhosphorImager quantitation of each band. The average ratios, including both the 2.8- and 1.9-kb bands, are indicated. (C) Model of proposed mechanism of silencing that depends

A

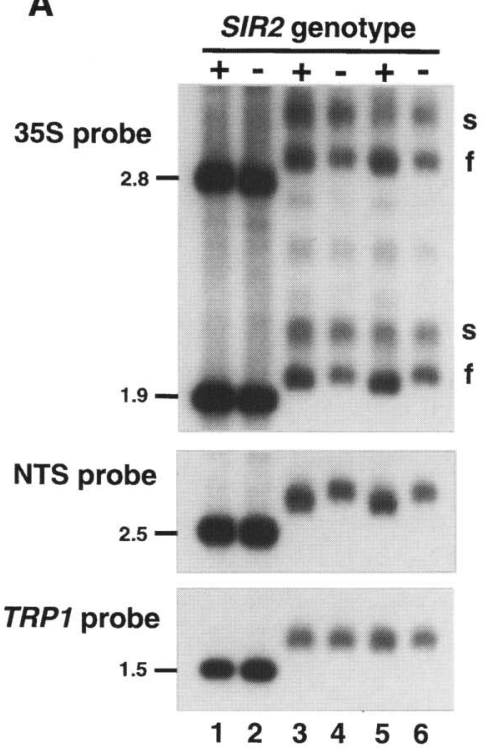

B

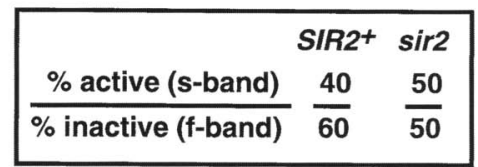

C

rDNA tandem array

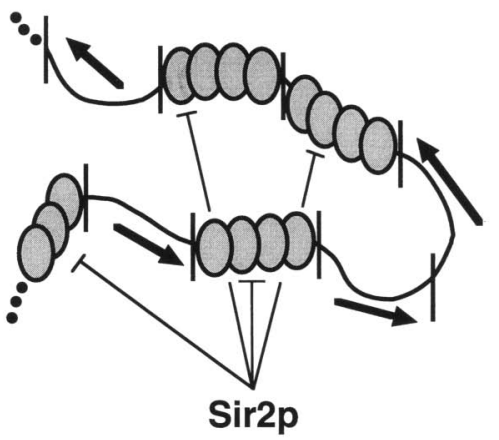

on the transcriptional status of a given rDNA gene copy within the tandem array. The distribution of active gene copies (arrows) is random, with the activity status of each gene copy not stable from generation to generation. Sir2p would be required for silencing in any of the inactive gene copies (shaded ovals). A marker in an active rDNA gene copy would also be active. 
Another silent information regulator gene, SIR4, appears to limit the degree of repression. (4) A specific chromatin structure was detected at the rDNA that requires SIR2 activity.

\section{Strength of $r D N A$ silencing depends on promoter properties}

The degree of telomeric silencing depends on promoter strength. The efficiency of URA3 silencing at telomeres is markedly increased by reducing the strength of the URA3 promoter through deletion of the activator PPR 1 (Renauld et al. 1993). Similarly, TRP1 lacking activation sequences was the most silenced marker tested near telomeres (Gottschling et al. 1990). The minimal TRP1 promoter driving mURA3 expression also lacks complete activation sequences (Kim et al. 1986). MET15 and LEU2 both had intact promoters, as did the Tyl element studied by Bryk et al. (1996). HIS3, which was not detectably silenced by rDNA, was also poorly silenced at telomeres (Gottschling et al. 1990). rDNA silencing is therefore not as potent as telomeric silencing but, like silencing at telomeres, depends on the strength of the particular promoter tested.

\section{SIR gene involvement in regulation of $r D N A$ silencing}

SIR2 has never before been implicated in silencing independent of SIR3 or SIR4. Interestingly, immunofluorescence has revealed that a large fraction of Sir2p normally localizes to the nucleolus, suggesting that its maior function is associated with rDNA (S. Gasser, pers. comm.). Given the large amount of rDNA, the yeast cell may use another set of factors that, along with SIR2, form and maintain repressive rDNA chromatin. This would prevent competition with the telomeres and $H M$ loci for other silencing factors such as Sir3p. Competition between the telomeres and HMR has been demonstrated previously (Buck and Shore 1995). Genes homologous to SIR2 (HST1, HST2, HST3, and HST4) were identified recently and shown to have roles in silencing and are candidates for functioning in rDNA silencing (Brachmann et al. 1995; Derbyshire et al. 1996).

Deletion of SIR4 significantly enhances rDNA silencing of MET15, suggesting a SIR4 regulatory function. Sir3p, Sir4p, and Raplp have been shown by immunofluorescence to colocalize with telomeres as foci within the nuclear periphery of $S$. cerevisiae (Palladino et al. 1993; Gotta et al. 1996; Maillet et al. 1996). It has been shown recently that loss of SIR 4 function delocalizes the telomeric foci, with $\mathrm{Sir} 3 \mathrm{p}$ relocalizing to the nucleolus (S. Gasser, pers. comm.), where it could have an as yet unknown function in rDNA silencing, perhaps in cooperation with Sir $2 p$. Sir $3 p$ and Sir $2 p$ have been shown recently to interact (Holmes et al. 1997). Raplp could also be released to act elsewhere. A Raplp-binding site exists in the rDNA that has been shown in vitro to be efficiently bound by Raplp (Buchman et al. 1988). However, it is unknown whether RAP1 has any function in rDNA silencing. In a sir4 mutant, Sir2p is no longer detectable at telomeres by either cross-linking or immunofluorescence, whereas the amount detected on rDNA increases (S. Gasser, pers. comm.). This could also explain the observed enhancement of rDNA silencing in a sir4 deletion strain. Consistent with this possibility, increases in SIR2 gene copy number enhance rDNA silencing (J.S. Smith and J.D. Boeke, in prep.).

Sir4p was shown recently to interact biochemically with Sir2p, Sir3p, Ubp3p, and a 69-kD protein (Moazed and Johnson 1996). Ubp3p is a deubiquitinating enzyme (Baker et al. 1992) that in the above study was shown to regulate telomeric and $H M$ loci silencing. Deletion of $U B P 3$ results in improved silencing at both locations. If Ubp3p were also involved in regulation of rDNA silencing, then loss of Sir4p could alter this regulation through the loss of Sir4p-Ubp3p interaction. In Bryk et al. (this issue), deletion of the UBC2 (RAD6) ubiquitin-conjugating enzyme gene resulted in loss of rDNA silencing, implicating a possible ubiquitin-mediated regulatory mechanism involved in rDNA silencing. Possible mechanisms of rDNA silencing regulation by SIR4 described above can now be tested.

\section{Chromatin and rDNA silencing}

Silencing of mURA3 caused by rDNA occurs only within the tandem array, not when an rDNA gene copy containing mURA3 is positioned at the LEU2 locus, suggesting that there may be a repressive chromatin structure specifically associated with the rDNA array. Inactive rDNA gene copies and the NTS were more accessible to psoralen cross-linking in a sir2 mutant, whereas active gene copies were minimally affected, consistent with a SIR2-dependent chromatin structure repressive to transcription. In a topoisomerase I mutant, the chromatin of actively transcribed rDNA gene copies was more accessible to psoralen, but the inactive gene copies were unaffected (Cavalli et al. 1996). Altered supercoiling was proposed to increase the accessibility of transcribed gene copies (Cavalli et al. 1996). Topoisomerase I and Sir2p therefore affect rDNA chromatin structure differently. The largest SIR2 affect on chromatin structure was at the NTS, where the regulatory elements for Pol I and Pol III transcription, as well as an origin of replication, are located. SIR2, therefore, potentially could influence all of these processes.

Histone hypoacetylation has been implicated in transcriptional silencing in $S$. cerevisiae, with histones $\mathrm{H} 3$ and $\mathrm{H} 4$ packaging the $H M$ silent cassettes displaying the same acetylation patterns as found in metazoan heterochromatin (Braunstein et al. 1996). SIR2 overexpression was shown previously to cause a decrease in histone acetylation (Braunstein et al. 1993). Regulation of nucleosome acetylation states within rDNA chromatin therefore could play a role in maintaining the Pol IIsilenced/recombination-silenced state.

\section{Model for intermediate rDNA silencing phenotypes}

The most striking phenotype of rDNA-mediated 
mURA3 silencing is that colonies are FOA $^{\mathrm{R}}$ yet still $\mathrm{Ura}^{+}$, similar to TPE. Switching between on and off transcriptional states was demonstrated by the red and white sectors of colonies that contain a telomeric $A D E 2$ gene (Gottschling et al. 1990). Large sector sizes in this assay indicate that switching occurs infrequently, which is phenotypically similar to classic position effect variegation caused by heterochromatin spreading in Drosophila. Using the MET15-based colony-color assay, we were unable to detect large reversible sectors, indicative of slow switching, in colonies containing Tyl-MET15 in the rDNA. An intermediate colony color was observed, which is more similar to centromeric and telomeric silencing in Schizosaccharomyces pombe (Allshire et al. 1994; Nimmo et al. 1994), where intermediate colored colonies were observed.

The chromatin structure of a single rDNA gene copy, including both the NTS and $35 \mathrm{~S}$ coding regions, changes dramatically depending on its Pol I transcription state (Dammann et al. 1993). In addition, the distribution of active gene copies in the array is random with the activity state of a specific gene copy not stably inherited (Dammann et al. 1995). This provides a potential stochastic on/off switch for controlling associated processes such as rDNA silencing. A model for rDNA silencing therefore can be developed in which $M U R A 3$ or $M E T 15$ expression rapidly alternates between two different states depending on the Pol I activity of the particular rDNA gene copy that the marker was inserted into (Fig. 7C). For example, active Pol I transcription could produce higher $m U R A 3$ expression, whereas an inactive gene copy would lack mURA3 expression. A SIR2-dependent repressive chromatin structure could silence the marker gene when its host rDNA gene copy is inactive. Such fast alternation between the two states would produce the phenotypic equivalent of a stably maintained intermediate expression level, and is highly consistent with all of our data.

\section{Biological functions of $r D N A$ silencing}

Why should the rDNA, which is a long uninterrupted stretch of DNA designed to be transcribed by Pol I and Pol III, contain a mechanism to silence transcription? A likely function could be to provide a chromatin state that excludes the recombinational machinery. Recombination rates within the rDNA are normally low relative to non-rDNA. sir2 mutations increase both meiotic and mitotic recombination rates in rDNA /Gottlieb and Esposito 1989), consistent with the loss of a protective chromatin environment. Other mutations that eliminate rDNA silencing also increase rDNA recombination rates (Bryk et al., this issue).

Another potential function of rDNA silencing could be to discourage the integration of foreign invaders like transposable elements into the array. The loss of one or a few rDNA gene copies by transposon insertion probably has no measurable effect on host viability, and therefore rDNA represents a potential "safe haven" for transposons. Indeed, the R1-R4 elements of inverte- brates are highly specialized for insertion into rDNA (Jakubczak et al. 1991; Burke et al. 1995). Tyl targeting upstream of Pol III-transcribed genes provides Tyl with a mechanism of integrating within the rDNA (Devine and Boeke 1996). The targeting of Tyl to the rDNA and its subsequent silencing is intriguing because another yeast retrotransposon, Ty5, targets its integration to silenced genomic regions (Zou et al. 1996). Interestingly, Ty3 can utilize the 5S rRNA gene as a target on an episomal plasmid, yet integration events into the tandem array do not occur (Chalker and Sandmeyer 1990), consistent with selective exclusion of retrotransposons. At the homologous recombination level, Pol II silencing could be a means of preventing the amplification of a Tyl element that happened to integrate into rDNA. Bryk et al. (this issue) show that Tyl transposition is indeed reduced when Tyl integrates into rDNA.

rRNAs are coordinately synthesized in most organisms, including $S$. cerevisiae. The levels of these RNA species change with different growth conditions such as nutrient availability and growth rate (Warner 1989). S. cerevisiae activates or inactivates rDNA gene copies as needed in response to growth conditions (Warner 1989; Dammann et al. 1993). SIR2 appears to affect this regulatory mechanism. We have shown that the proportion of transcriptionally active rDNA gene copies consistently increases in the absence of sir2. Loss of a SIR2dependent rDNA chromatin structure may increase the probability that a particular rDNA gene copy is actively transcribed, which potentially could have dramatic effects on the overall levels of rRNA synthesis. The possible effects on $5 S$ Pol III transcription or rDNA replication has not yet been addressed.

Bryk et al. (this issue) demonstrate that transposition of Tyl embedded in the rDNA is repressed in a UBC2-, SIR2-, and TOP1-dependent manner. This repression was a result of silencing of transcription from the Tyl promoter. Ubc2p is an E2 ubiquitin-conjugating enzyme that can polyubiquitinate the core histones $\mathrm{H} 2 \mathrm{~A}$ and $\mathrm{H} 2 \mathrm{~B}$, in vitro. Consistent with a role for chromatin structure, they also show that changing the stoichiometry of $\mathrm{H} 2 \mathrm{~A}$ and $\mathrm{H} 2 \mathrm{~B}$ by deleting one gene pair also relaxes rDNA silencing. These findings by Bryk et al. (this issue) provide independent evidence for an unusual chromatin structure in the rDNA tandem array that is repressive to Pol II transcription. Finally, the mURA3 and MET15 marker systems described here provide versatile and sensitive reporters for the identification of other genes that are involved in the formation and maintenance of the repressive chromatin structure within yeast $\mathrm{rDNA}$, which could provide new insights into the formation and function of yeast "heterochromatin."

\section{Materials and methods}

Plasmids

mURA3-marked GAL-Ty1 plasmids were constructed as follows. pJEF1114 is a $2 \mu, T R P 1$ vector that contains an unmarked Tyl element fused to the GAL1 promoter (Natsoulis et al. 1989). The BamHI site between the 3' LTR and TRP1 marker 
was filled in, producing pIEF1712. The $3^{\prime}$ end of Tyl in pJEF1712 was replaced with a Sall-NcoI fragment from pD123 (Ji et al. 1993), containing a BamHI site at nucleotide 5561 in Tyl, producing pJSS19. A promoterless URA3 fragment was PCR-amplified using primers JB1006 (5'-CGCGGATCCATGTCGAAAGCTACATAT-3') and JB1007 (5'-CGCAGATCTTAGTTTTGCTGGCCGCAT-3'), cut with BamHI and BgllI (sites underlined), and ligated into the BamHI site of pISS19, producing pISS20-1. A TRP1 promoter [nucleotides -209 to -1 [Kim et al. 1986)] was PCR-amplified from pRS404 (Sikorski and Hieter 1989), using primers JB1003 (5'-CGCGGATCCTATGACGCCAGATGGCA-3') and JB930 (5'-GCGAGATCTCCAAGCTGCCTTTG-3'), digested with BamHI and Bg/II, and ligated into the BamHI site of pISS20-1, producing pISS22-7. The 3' end of unmarked Ty1 in pIEF1695 (HIS3 plasmid marker, J.D. Boeke, unpubl.) was replaced with the $3^{\prime}$ end of $m U R A 3-$ marked Tyl from pISS22-7 by swapping Sall-NcoI fragments, producing pJSS36-6.

MET15-marked Ty1 plasmid pJSS46-8 was constructed by inserting a MET15 PCR fragment consisting of nucleotides -333 to +1332 amplified from plasmid pGC3 (Cost and Boeke 1996), using primers JB1266 (5'-CGCGGATCCTTGAGGTCACATGATCGC-3') and JB1265 (5'-CGCAGATCTCATGGTTTTTGGCCAGCG-3') into the BamHI site of pD123.

To construct pISS51-9, containing the mURA3-HIS3 reporter, an amino-terminal BamHI-NcoI fragment of mURA3 from pISS22-7 and a carboxy-terminal NcoI-HindIII fragment of URA3 from YEp24 were ligated together into BamHI-HindIII linearized pRS425 (Christianson et al. 1992), to regenerate mURA3 with its native transcription terminator (pISS42-1). HIS3 was inserted downstream of mURA3 by ligating a HIS3 PCR cassette with Xhol termini amplified from pRS403 (Sikorski and Hieter 1989), using primers JB1307 (5'-CGCCTCGAGATTGTACTGAGAGTGCACC-3') and JB1308 (5' -CGCCTCGAGCTGTGCGGTATTTCACACCG-3') into the XhoI site downstream of $m U R A 3$ in JSS42-1.

pISS60-2 was constructed by ligating the $5^{\prime}$ and $3^{\prime}$ BgIII fragments of an rDNA unit into the BamHI site of pRS405 to reconstruct a full gene copy in pISS49-5. A BamHI fragment from pJSS36-6 consisting of $m U R A 3$ and the Tyl 3' LTR was ligated into the $B g / I I$ site of the $25 \mathrm{~S}$ rDNA of pISS49-5 in the opposite orientation as rRNA transcription.

pCAR237 was constructed by inserting a HindIII genomic fragment containing SIR2 into the HindIII site of pRS415 (Sikorski and Hieter 1989). The pBS-URA template for producing an antisense URA3 probe for Northern analysis was constructed by ligating a promoterless URA3 PCR product into the BamHI site of pBluescript II KS(-).

\section{Media and strains}

Unless stated otherwise, media used were as described previously (Rose et al. 1990). Tyl transposition induction medium (YNB/CAA+Trp galactose) consisted of yeast nutrient broth (YNB) supplemented with $2 \%$ casamino acids, $2 \%$ galactose, $160 \mu \mathrm{M}$ adenine, $800 \mu \mathrm{M}$ tryptophan. SC (FOA) medium contained 5-FOA at $2 \mathrm{mg} / \mathrm{ml}$ and glucose at $2 \% . \mathrm{Pb}^{2+}$-containing media (MLA) was described previously (Cost and Boeke 1996). Yeast strains are listed in Table 1.

\section{Ty1 transposition and selection}

JS50-2 was patched onto SC-His glucose and incubated for 1 day at $30^{\circ} \mathrm{C}$. IS 216 was patched on SC-Ura glucose. These patches were replica-plated to induction medium (YNB/CAA+Trp galactose) and incubated for 5 days at $22^{\circ} \mathrm{C}$. These patches were then replica-plated to SC-His glucose for IS50-2 and SC-Ura glucose for IS216 and incubated for 2 days at $30^{\circ} \mathrm{C}$ to stop transposition, followed by replica-plating to YPD to allow for donor Ty1 plasmid loss for 1 day at $30^{\circ} \mathrm{C}$. IS216 patches were then replica-plated to SC (FOA). IS50-2 cells were scraped from the YPD patches, diluted and spread on SC (FOA) plates and incubated for 3 days at $30^{\circ} \mathrm{C}$. FOA ${ }^{\mathrm{R}}$ colonies were replica-plated to $\mathrm{SC}-\mathrm{Ura}$ glucose to identify $\mathrm{FOA}^{\mathrm{R}} / \mathrm{Ura}^{+}$isolates. JS216 cells were scraped from the FOA patches, diluted in water, spread on $\mathrm{Pb}$-containing MLA plates, and incubated for $5-10$ days at $30^{\circ} \mathrm{C}$ for color analysis. Transposition induction generally results in $50 \%-70 \%$ of cells receiving one or more transposition event for Ty1-mURA3 and Ty1-MET15.

\section{Cloning of Ty1-mURA3 genomic integration events}

Genomic DNA of $\mathrm{FOA}^{\mathrm{R}} / \mathrm{Ura}^{+}$clones was isolated (Boeke et al. $1985)$ and $15 \mu$ l was digested with HindIII and separated on $0.7 \%$ agarose. HindIII cleaves once in Ty1-mURA3 and at an unknown site in flanking genomic DNA (Fig. 1C). Regions of the gel containing the Ty1-mURA3 fragment were excised. A minilibrary was constructed by ligating the purified DNA into the HindIII site of pBluescript II KS(-), and transforming into $E$. coli strain $\mathrm{MH} 6$ (which has a pyrF mutation). Carbenicillin resistant colonies were replica-plated to $\mathrm{M} 9$ medium lacking uracil to select for $\mathrm{Pyr}^{+}\left(\mathrm{Ura}^{+}\right)$transformants. Integration sites of the cloned insertions were sequenced using primer JB66 15'GAGGAGAACTTCTAGTATAT- $3^{\prime}$ ), which reads out from Tyl into flanking DNA (Fig. 1A).

\section{RNA blot analysis}

Saturated YPD cultures were diluted to an $\mathrm{A}_{600}$ of 0.2 in YPD and grown at $30^{\circ} \mathrm{C}$ to mid-log phase $\left(A_{600}\right.$ of $\left.1.4-1.6\right)$. Forty micrograms of total RNA, isolated as described by Chapman and Boeke (1991), was separated on a formaldehyde-containing $1.2 \%$ agarose gel and transferred to Genescreen Plus (NENDupont) in $10 \times$ SSC. The filter was probed with an antisense $U R A 3$ RNA probe labeled with $\left[\alpha{ }^{32}\right.$ P]UTP $(800 \mathrm{Ci} / \mathrm{mmole})$. The URA3 RNA probe was transcribed by T7 RNA polymerase from pBS-URA3 linearized with StuI, producing a 363-nucleotide antisense probe. The filter was prehybridized in $10 \mathrm{ml}$ of $5 \times$ SSPE, $5 \times$ Denhardt's solution, $1 \%$ SDS, $50 \%$ formamide (wt) vol), and $100 \mu \mathrm{g} / \mathrm{ml}$ boiled herring sperm DNA at $60^{\circ} \mathrm{C}$ for $3 \mathrm{hr}$, followed by hybridization in the above solution without herring sperm DNA at $60^{\circ} \mathrm{C}$ for $16 \mathrm{hr}$. The filter was washed twice at room temperature in $2 \times \mathrm{SSC} / 0.1 \% \mathrm{SDS}$, twice at room temperature in $0.2 \times \mathrm{SSC} / 0.1 \% \mathrm{SDS}$, and twice at $42^{\circ} \mathrm{C}$ in $0.2 \times \mathrm{SSC} /$ $0.1 \%$ SDS. The filter was imaged on a Molecular Dynamics PhosphorImager.

\section{Identification and mapping of Ty1 insertions in rDNA}

Colony PCR reactions contained $10 \mathrm{~mm}$ Tris- $\mathrm{HCl}$ at $\mathrm{pH} 8.4,50$ $\mathrm{mM} \mathrm{KCl}, 1.5 \mathrm{~mm} \mathrm{MgCl}_{2}, 200 \mu \mathrm{M}$ each dNTP, 19 pmoles of each primer, and 1 unit Amplitaq (Perkin Elmer). Approximately $3.5 \times 10^{5}$ cells from a YPD grown colony were added to each 20 $\mu \mathrm{l}$ reaction. PCR was done in a GeneAmp 9600 (Perkin Elmer; 5 min, $94^{\circ} \mathrm{C}, 1$ cycle; $1 \mathrm{~min}, 94^{\circ} \mathrm{C}, 1 \mathrm{~min}, 57^{\circ} \mathrm{C}, 1 \mathrm{~min}, 72^{\circ} \mathrm{C}, 30$ cycles). Products were separated on $1 \%$ agarose and the insertion points were inferred from product sizes. The Tyl-mURA3 specific primer was JB1160 (5'-CATATTTGAGAAGATGCGGCCAGC-3') and the Ty1-MET15 specific primer was JB1309 $\left(5^{\prime}\right.$-TGCCATTTTGCGATCATGTGACCTC- $\left.3^{\prime}\right)$. rDNA specific primers were JB1161 (5'-GATAGTTTAACGGAAACGCAGGTG-3'), JB1162 (5'-GTAGTTGGGAGGTACTTCATGCGA-3'), JB1163 (5' -ATGCTACTTGCAAAATATCATACC- 
3'), JB1164 (5'-CTTAAAAGAAGAAGCAACAAGCAG-3'), and JB1168 (5'-CTTTCTAAGTGGGTACTGGCAGGA-3').

PCR-mediated deletion of SIR genes and integration of dual marker into $r D N A$

SIR1, SIR2, SIR3, and SIR4 open reading frames (ORFs) were precisely deleted by PCR-mediated gene disruption as described (Baudin et al. 1993; Lorenz et al. 1995), amplifying HIS3 using primers containing 5 ' flanking sequences corresponding to the SIR genes. Sir ${ }^{-}$colonies were identified by a mating test.

To integrate the dual-marker reporter into specific positions in rDNA, primers were designed to amplify the pRS vector polylinker, and any sequences inserted there. For example, to integrate the reporter downstream of the 5S rDNA, primers JB1269 (5'-GCAGTTTCTAGGGAATGATGATGGCAAGTTCCAGAGAGGATACGACTCACTATAGGGCG-3') and JB1270 (5'-CCTCTTTCTTCTTCCCAGTAGCCTGTTCСTTTTACGCTGAAGGGAACAAAAGCTGGAGC- ${ }^{\prime}$ ), were used for amplification. Underlined sequences are complementary to nucleotides $3102-3121$ and $3250-3231$ of pR5425, respectively. The bold sequences represent nucleotides 590 and 591 of the rDNA (Skryabin et al. 1984), respectively, indicating the location of integration. This integrates the reporter without deleting or duplicating rDNA sequence. Other rDNA primer pair sequences are available upon request.

\section{Psoralen cross-linking}

Fresh 100-ml yeast extract, peptone, dextrose (YPD) cultures were inoculated from saturated cultures YPD cultures to an $\mathrm{A}_{600}$ of 0.3 and grown for $6 \mathrm{hr}$ at $30^{\circ} \mathrm{C}$ into log phase. Crosslinking with 4, 5', 8-trimethylpsoralen (Sigma) using a longwave UV lamp (model B-100A; Ultraviolet Products, Inc.) was as described previously (Dammann et al. 1993). Approximately $5 \times 10^{8}$ cells were washed with ice-cold $\mathrm{H}_{2} \mathrm{O}$ and resuspended in $1.4 \mathrm{ml}$ cold $10 \mathrm{~mm}$ Tris- $\mathrm{HCl}(\mathrm{pH} 7.6), 1 \mathrm{~mm}$ EDTA (TE) in a six-well tissue culture plate. Seventy microliters of $200 \mu \mathrm{g} / \mathrm{ml}$ psoralen in $100 \%$ ethanol was added to each well and UV-irradiated for $5 \mathrm{~min}$ on ice at a distance of $6 \mathrm{~cm}$ five times. Cells were washed, spheroplasted with Zymolyase at $37^{\circ} \mathrm{C}$, lysed, proteinase $\mathrm{K}$-treated, phenol/chloroform extracted, and ethanol precipitated. Total nucleic acid was resuspended in TE and normalized to $A_{260}$ of 0.1 . DNA (10 $\left.\mu 1\right)$ was digested overnight at $37^{\circ} \mathrm{C}$ with EcoRI in a $30 \mu \mathrm{l}$ reaction containing $80 \mathrm{ng} / \mu \mathrm{l}$ of RNase A. DNA was separated on $1.3 \%$ agarose $(14.5 \times 24 \mathrm{~cm})$ at $60 \mathrm{~V}$ for $24 \mathrm{hr}$. Cross-linking was reversed in a Stratagene Stratalinker at $0.6 \mathrm{~J} / \mathrm{cm}^{2}$. DNA was transferred to GeneScreen Plus in $10 \times$ SSC and hybridized with rDNA-specific probes A (NTS) or $\mathrm{B}$ (35S), or a TRP1-specific probe.

\section{Acknowledgments}

We thank Dan Gottschling, Lorraine Pillus, Scott Devine, and other members of the Boeke laboratory for helpful discussions and comments. We also thank Carrie Brachmann for the SIR2 plasmid, valuable advice, and critical reading of the manuscript; Eleanor Hoff for critical reading of the manuscript; Greg Cost for assistance with the MET15 system; Mary Bryk, M. Joan Curcio, James Broach, Monica Gotta, and Susan Gasser for communicating results prior to publication; and David Bonnyay for technical assistance. This work was supported by National Institutes of Health grants GM36481 and CA16519 to J.D.B. J.S.S. is a Fellow of the Leukemia Society of America.

The publication costs of this article were defrayed in part by payment of page charges. This article must therefore be hereby marked "advertisement" in accordance with 18 USC section 1734 solely to indicate this fact.

\section{References}

Allshire, R.C., J.-P. Javerzat, N.J. Redhead, and G. Cranston. 1994. Position effect variegation at fission yeast centromeres. Cell 76: 157-169.

Aparicio, O.M., B.L. Billington, and D.E. Gottschling. 1991. Modifiers of position effect are shared between telomeric and silent mating-type loci in S. cerevisiae. Cell 66: 12791287.

Baker, R.T., J.W. Tobias, and A. Varshavsky. 1992. Ubiquitinspecific proteases of Saccharomyces cerevisiae. Cloning of $U B P 2$ and $U B P 3$, and functional analysis of the UBP gene family. J. Biol. Chem. 267: 23364-23375.

Baudin, A., O. Ozier-Kalogeropoulos, A. Denouel, F. Lacroute, and C. Cullin. 1993. A simple and efficient method for direct gene deletion in Saccharomyces cerevisiae. Nucleic Acids Res. 21: 3329-3330.

Boeke, J.D., F. LaCroute, and G.R. Fink. 1984. A positive selection for mutants lacking orotidine-5'-phosphate decarboxylase activity in yeast: 5-Fluoro-orotic acid resistance. Mol. \& Gen. Genet. 197: 345-346.

Boeke, J.D., D.J. Garfinkel, C.A. Styles, and G.R. Fink. 1985. Ty elements transpose through an RNA intermediate. Cell 40: 491-500.

Boeke, J.D., H. Xu, and G.R. Fink. 1988. A general method for the chromosomal amplification of genes in yeast. Science 239: 280-282.

Brachmann, C.B., J.M. Sherman, S.E. Devine, E.E. Cameron, L. Pillus, and J.D. Boeke. 1995. The SIR2 gene family, conserved from bacteria to humans, functions in silencing, cell cycle progression, and chromosome stability. Genes \& Dev. 9: 2888-2902.

Braunstein, M., A.B. Rose, S.G. Holmes, C.D. Allis, and J.R. Broach. 1993. Transcriptional silencing in yeast is associated with reduced nucleosome acetylation. Genes \& Dev. 7: 592604.

Braunstein, M., R.E. Sobel, C.D. Allis, B.M. Turner, and J.R. Broach. 1996. Efficient transcriptional silencing in Saccharomyces cerevisiae requires a heterochromatin histone acetylation pattern. Mol. Cell. Biol. 16: 4349-4356.

Brill, S.J., S. DiNardo, K. Voelkel-Meiman, and R. Sternglanz. 1987. Need for DNA topoisomerase activity as a swivel for DNA replication of ribosomal RNA. Nature 326: 414-416.

Bryk, M., M. Banerjee, M. Murphy, K.E. Knudsen, D.J. Garfinkel, and M.J. Curcio. 1997. A specialized chromatin structure in the RDN1 locus of yeast causes transcriptional silencing of Tyl elements. Genes \& Dev. (this issue).

Buchman, A.R., N.F. Lue, and R.D. Kornberg. 1988. Connections between transcriptional activators, silencers, and telomeres as revealed by functional analysis of a yeast DNAbinding protein. Mol. Cell. Biol. 8: 5086-5099.

Buck, S.W. and D. Shore. 1995. Action of a RAPl carboxy-terminal silencing domain reveals an underlying competition between HMR and telomeres in yeast. Genes \& Dev. 9: 370384.

Burke, W.D., F. Muller, and T.H. Eickbush. 1995. R4, a non-LTR retrotransposon specific to the large subunit rRNA genes of nematodes. Nucleic Acids Res. 23: 4628-4634.

Cavalli, G., D. Bachmann, and F. Thoma. 1996. Inactivation of topoisomerases affects transcription-dependent chromatin transitions in rDNA but not in a gene transcribed by RNA polymerase II. EMBO I. 15: 590-597. 
Chalker, D.L. and S.B. Sandmeyer. 1990. Transfer RNA genes are genomic targets for de novo transposition of the yeast retrotransposon Ty3. Genetics 126: 837-850.

Chapman, K.B. and J.D. Boeke. 1991. Isolation and characterization of the gene encoding yeast debranching enzyme. Cell 65: 483-492.

Christianson, T.W., R.S. Sikorski, M. Dante, J.H. Shero, and P. Hieter. 1992. Multifunctional yeast high-copy-number shuttle vectors. Gene 110: 119-122.

Christman, M.F., F.S. Dietrich, and G.R. Fink. 1988. Mitotic recombination in the rDNA of $S$. cerevisiae is suppressed by the combined action of DNA topoisomerases I and II. Cell 55: 413-425.

Cost, G.J. and J.D. Boeke. 1996. A useful colony colour phenotype associated with the yeast selectable/counterselectable marker MET15. Yeast 12: 939-941.

Curcio, M.J. and D.J. Garfinkel. 1991. Single-step selection for Tyl element retrotransposition. Proc. Natl. Acad. Sci. 88: 936-940.

Dammann, R., R. Lucchini, T. Koller, and J.M. Sogo. 1993. Chromatin structures and transcription of rDNA in yeast Saccharomyces cerevisiae. Nucleic Acids Res. 21:23312338.

-1995. Transcription in the yeast rRNA gene locus: Distribution of the active gene copies and chromatin structure of their flanking regulatory sequences. Mol. Cell. Biol. 15: 5294-5303.

Derbyshire, M.K., K.G. Weinstock, and J.N. Strathern. 1996. HST1, a new member of the SIR2 family of genes. Yeast 12: 631-640.

Devine, S.E. and J.D. Boeke. 1996. Integration of the yeast retrotransposon Tyl is targeted to regions upstream of genes transcribed by RNA polymerase III. Genes \& Dev. 10: 620633.

Gangloff, S., J.P. McDonald, C. Bendixen, L. Arthur, and R. Rothstein. 1994. The yeast type I topoisomerase Top3 interacts with Sgs1, a DNA helicase homolog: A potential eukaryotic reverse gyrase. Mol. Cell. Biol. 14: 8391-8398.

Gotta, M. T. Laroche, A. Formenton, L. Maillet, H. Scherthan, and S.M. Gasser. 1996. The clustering of telomeres and colocalization with Rap1, Sir3, and Sir4 proteins in wild-type Saccharomyces cerevisiae. I. Cell Biol. 134: 1349-1363.

Gottlieb, S. and R.E. Esposito. 1989. A new role for a yeast transcriptional silencer gene, SIR2, in regulation of recombination in ribosomal DNA. Cell 56: 771-776.

Gottschling, D.E. 1992. Telomere-proximal DNA in Saccharomyces cerevisiae is refractory to methyltransferase activity in vivo. Proc. Natl. Acad. Sci. 89: 4062-4065.

Gottschling, D.E., O.M. Aparicio, B.L. Billington, and V.A. Zakian. 1990. Position effect at $S$. cerevisiae telomeres: Reversible repression of Pol II transcription. Cell 63: 751-762.

Hecht, A., T. Laroche, S. Strahl-Bolsinger, S.M. Gasser, and M. Grunstein. 1995. Histone H3 and H4 N-termini interact with SIR3 and SIR4 proteins: A molecular model for the formation of heterochromatin in yeast. Cell 80: 583-592.

Holmes, S.G., A.B. Rose, E. Saez, S. Sayegh, K. Steuerle, and J.R. Broach. 1997. Hyperactivation of the silencing proteins, Sir2p and Sir3p, causes chromosome loss. Genetics (in press).

Jakubczak, J.L., W.D. Burke, and T.D. Eickbush. 1991. Retrotransposable elements R1 and R2 interrupt the rRNA genes of most insects. Proc. Natl. Acad. Sci. 88: 3295-3299.

Ji, H., D.P. Moore, M.A. Blomberg, L.T. Braiterman, D.F. Voytas, G. Natsoulis, and J.D. Boeke. 1993. Hotspots for unselected Tyl transposition events on yeast chromosome III are near tRNA genes and LTR sequences. Cell 73: 1007-1018.

Keil, R.L. and A.D. McWilliams. 1993. A gene with specific and global effects on recombination of sequences from tandemly repeated genes in Saccharomyces cerevisiae. Genetics 135: $711-718$.

Kim, R.A. and J.C. Wang. 1989. A subthreshold level of DNA topoisomerases leads to the excision of yeast rDNA as extrachromosomal rings. Cell 57: 975-985.

Kim, S., J. Mellor, A.J. Kingsman, and S.M. Kingsman. 1986. Multiple control elements in the TRP1 promoter of Saccharomyces cerevisiae. Mol. Cell. Biol. 6: 4251-4258.

Kingston, R.E., C.A. Bunker, and A.N. Imbalzano. 1996. Repression and activation by multiprotein complexes that alter chromatin structure. Genes \& Dev. 10: 905-920.

Kostriken, R., J.N. Strathern, A.J.S. Klar, J.B. Hicks, and F. Heffron. 1983. A site-specific endonuclease essential for matingtype switching in Saccharomyces cerevisiae. Cell 35: $167-$ 174.

Loo, S. and J. Rine. 1994. Silencers and domains of generalized repression. Science 264: 1768-1771.

. 1995. Silencing and heritable domains of gene expression. Annu, Rev. Biol. Dev. 11: 519-548.

Lorenz, M.C., R.S. Muir, E. Lim, J. McElver, S.C. Weber, and J. Heitman. 1995. Gene disruption with PCR products in Saccharomyces cerevisiae. Gene 158: 113-117.

Maillet, L., C. Boscheron, M. Gotta, S. Marcand, E. Gilson, and S.M. Gasser. 1996. Evidence for silencing compartments within the yeast nucleus: A role for telomere proximity and Sir protein concentration in silencer-mediated repression. Genes \& Dev. 10: 1796-1811.

Moazed, D. and A.D. Johnson. 1996. A deubiquitinating enzyme interacts with SIR4 and regulates silencing in S. cerevisiae. Cell 86: 667-677.

Natsoulis, G., W. Thomas, M.-C. Roghmann, F. Winston, and J.D. Boeke. 1989. Tyl transposition in Saccharomyces cerevisiae is nonrandom. Genetics 123: 269-279.

Nimmo, E.R., G. Cranston, and R.C. Allshire. 1994. Telomereassociated chromosome breakage in fission yeast results in variegated expression of adjacent genes. EMBO $T$. 13: 38013811.

Ono, B., N. Ishii, S. Fujino, and I. Aoyama. 1991. Role of hydrosulfide ions in methylmercury resistance in Saccharomyces cerevisiae. Appl. Env. Microbiol. 57: 3183-3186.

Palladino, F., T. Laroche, E. Gilson, A. Axelrod, L. Pillus, and S.M. Gasser. 1993. SIR3 and SIR4 proteins are required for the positioning and integrity of yeast telomeres. Cell 75: 543-555.

Petes, T.D. and D. Botstein. 1977. Simple Mendelian inheritance of the reiterated ribosomal DNA of yeast. Proc. Natl. Acad. Sci. 74: 5091-5095.

Philippsen, P., M. Thomas, R.A. Kramer, and R.W. Davis. 1978. Unique arrangement of coding sequences for $5 \mathrm{~S}, 5.8 \mathrm{~S}, 18 \mathrm{~S}$, and $25 \mathrm{~S}$ ribosomal RNA in Saccharomyces cerevisiae as determined by R-loop and hybridization analysis. J. Mol. Biol. 123: 387-404.

Pillus, L. and J. Rine. 1989. Epigenetic inheritance of transcriptional states in S. cerevisiae. Cell 59: 637-647.

Renauld, H., O.M. Aparicio, P.D. Zierath, B.L. Billington, S.K. Chhablani, and D.E. Gottschling. 1993. Silent domains are assembled continuously from the telomere and are defined by promoter distance and strength, and by SIR3 dosage. Genes \& Dev. 7: 1133-1145.

Rose, M.D., F. Winston, and P. Hieter. 1990. Methods in yeast genetics. A laboratory course manual. Cold Spring Harbor Laboratory Press, Cold Spring Harbor, NY.

Rustchenko, E.P. and F. Sherman. 1994. Physical constitution of ribosomal genes in common strains of Saccharomyces cerevisiae. Yeast 10: 1157-1171. 
Schnell, R. and J. Rine. 1986. A position effect on the expression of a tRNA gene mediated by the SIR genes of Saccharomyces cerevisiae. Mol. Cell. Biol. 6: 494-501.

Sikorski, R.S. and P. Hieter. 1989. A system of shuttle vectors and yeast host strains designed for efficient manipulation of DNA in Saccharomyces cerevisiae. Genetics 122: 19-27.

Singh, J. and A.J.S. Klar. 1992. Active genes in budding yeast display enhanced in vivo accessibility to foreign DNA methylases: A novel in vivo probe for chromatin structure of yeast. Genes \& Dev. 6: 186-196.

Skryabin, K.G., M.A. Eldarov, V.L. Larionov, A.A. Bayev, J. Klootwijk, V.C.H. F.d. Regt, G.M. Veldman, R.J. Planta, O.I. Georgiev, and A.A. Hadjiolov. 1984. Structure and function of the nontranscribed spacer regions of yeast rDNA. Nucleic Acids Res. 12: 2955-2968.

Strathern, J.N., A.J. Klar, J.B. Hicks, J.A. Abraham, J.M. Ivy, K.A. Nasmyth, and C. McGill. 1982. Homothallic switching of yeast mating-type cassettes is initiated by a double-stranded cut in the MAT locus. Cell 31: 183-192.

Szostak, J.W. and R. Wu. 1980. Unequal crossing over in the ribosomal DNA of Saccharomyces cerevisiae. Nature 284: 426-430.

Thompson, J.S., A. Hecht, and M. Grunstein. 1994. Histones and the regulation of heterochromatin in yeast. Cold Spring Harbor Symp. Quant. Biol. 58: 247-256.

Warner, J.R. 1989. Synthesis of ribosomes in Saccharomyces cerevisiae. Microbiol. Rev. 53: 256-271.

Winston, F., C. Dollard, and S.L. Ricupero-Hovasse. 1995. Construction of a set of convenient Saccharomyces cerevisiae strains that are isogenic to S288C. Yeast 11: 53-55.

Zou, S., N. Ke, J.M. Kim, and D.F. Voytas. 1996. The Saccharomyces retrotransposon Ty5 integrates preferentially into regions of silent chromatin at the telomeres and mating loci. Genes \& Dev. 10: 634-645. 


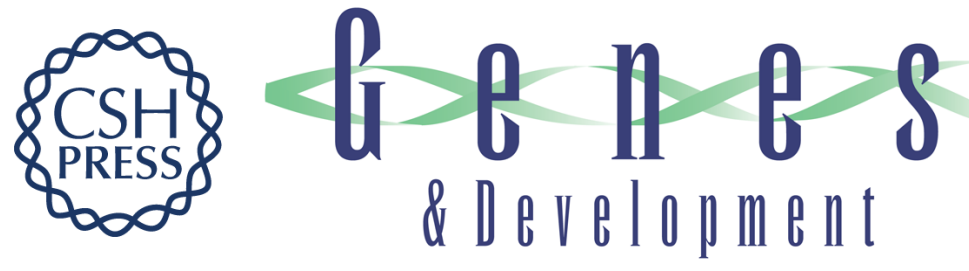

\section{An unusual form of transcriptional silencing in yeast ribosomal DNA.}

J S Smith and J D Boeke

Genes Dev. 1997, 11:

Access the most recent version at doi:10.1101/gad.11.2.241

References This article cites 62 articles, 29 of which can be accessed free at: http://genesdev.cshlp.org/content/11/2/241.full.html\#ref-list-1

License

Email Alerting

Receive free email alerts when new articles cite this article - sign up in the box at the top Service right corner of the article or click here.

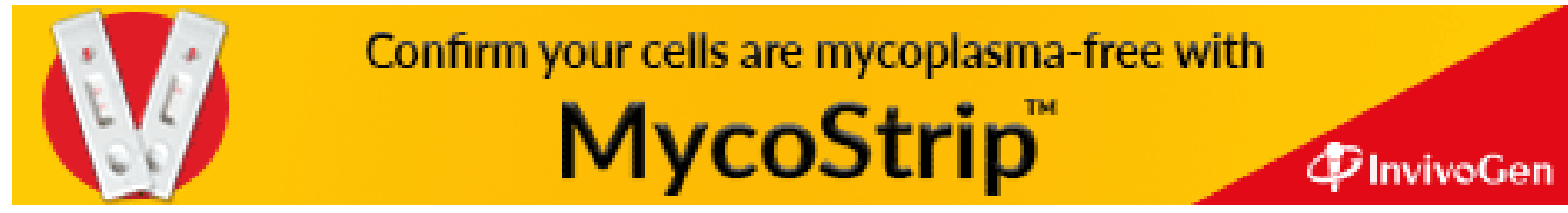

